02;04;09

\title{
Наблюдение расщепления Раби уровней атома кислорода в плазме филаментов, созданных фемтосекундным импульсом титан-сапфирового лазера
}

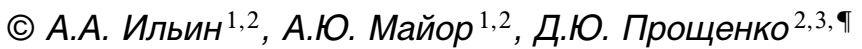 \\ ${ }^{1}$ Институт автоматики и процессов управления ДВО РАН, Владивосток, \\ Россия \\ ${ }^{2}$ Дальневосточный федеральный университет, Владивосток, Россия \\ ${ }^{3}$ Морской государственный университет им. адм. Г.И. Невельского, \\ Владивосток, Россия \\ ؟E-mail: dima.prsk@mail.ru
}

Поступило в Редакцию 3 мая 2018 г.

Исследована динамика спектра излучения остросфокусированного фемтосекундного лазерного импульса при филаментации в воздухе. В спектре прошедшего через область филаментации лазерного импульса зарегистрирован пик на длине волны $735 \mathrm{~nm}$, а также падение интенсивности лазерного излучения на основной длине волны излучения. Показано, что появление пика, скорее всего, связано с расщеплением Раби уровней О I и разрывом $L S$-связи для уровня $3 \mathrm{p}^{5} \mathrm{P}$ в сильном лазерном поле.

DOI: $10.21883 /$ PJTF.2018.21.46851.17364

Явление филаментации, впервые зарегистрированное в середине 60-х годов прошлого столетия [1], до сих пор стимулирует повышенный интерес к изучению особенностей физических процессов, сопровождающих этот феномен. Уникальные свойства данного явления нашли широкое применение во всевозможных прикладных областях, в частности в задачах по микромодификации различных материалов, в области флуоресцентной и эмиссионной спектроскопии, при направленной передаче СВЧ-излучения, в задачах по атмосферному зондированию [2,3]. При распространении интенсивных ультракоротких лазерных импульсов (УКИ) как в конденсированных средах [4], так и в атмосфере [5] в результате совместного проявления различных 


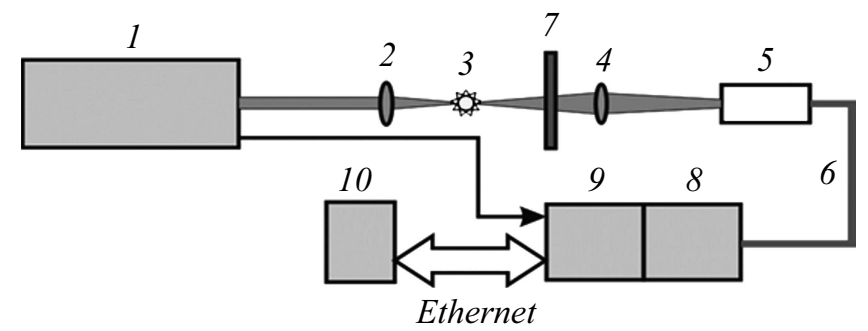

Рис. 1. Экспериментальная установка. 1 - фемтосекундный лазерный комплекс Tsunami+Spitfire 40f-1k-5W, 2, 4 - линзы, фокус $50 \mathrm{~mm}, 3$ - плазма филамента, 5 - опаловый рассеиватель, 6 - кварцевый световод, 7 - фильтр CC1, 8 - спектрограф SP 2300i, 9 - камера PI-MAX3, 10 - компьютер.

нелинейно-оптических процессов наблюдается возникновение динамического баланса между конкурирующими процессами керровской самофокусировки и плазменной дефокусировки, что в итоге приводит к зарождению филаментов. В свою очередь для остросфокусированных лазерных импульсов превалирующую роль в процессе филаментации играет геометрическая фокусировка, при этом аберрации линз могут вносить весомый вклад в итоговую картину филаментации [6]. Филаментация сопровождается значительным уширением спектра УКИ, однако в плазме филаментов также возможна трансформация спектра лазерного импульса. В работах $[7,8]$ продемонстрировано появление широкополосных сателлитов, сдвинутых в стоксову и антистоксову области спектра для второго слабосфокусированного лазерного импульса в атмосфере кислорода. В связи с этим при острой фокусировке излучения наряду с особенностями генерации титан-сапфировых (Ti: $\mathrm{Sa})$ лазеров (наличие усиленного спонтанного излучения и постимпульсов [9]) возможно наблюдение боковых сателлитов, сдвинутых относительно центральной длины волны лазерного излучения. Таким образом, целью настоящей работы является исследование динамики спектра излучения Ti: Sa-лазерного комплекса, прошедшего через область филаментации.

В работе реализована экспериментальная установка, представленная на рис. 1. С помощью фемтосекундного лазерного комплекса Tsunami + Spitfire 40f-1k-5W (1) генерировались импульсы на центральной длине волны $800 \mathrm{~nm}$ (полуширина FWHM $=25 \mathrm{~nm}$ ) длительностью

2 Письма в ЖТФ, 2018, том 44, вып. 21 


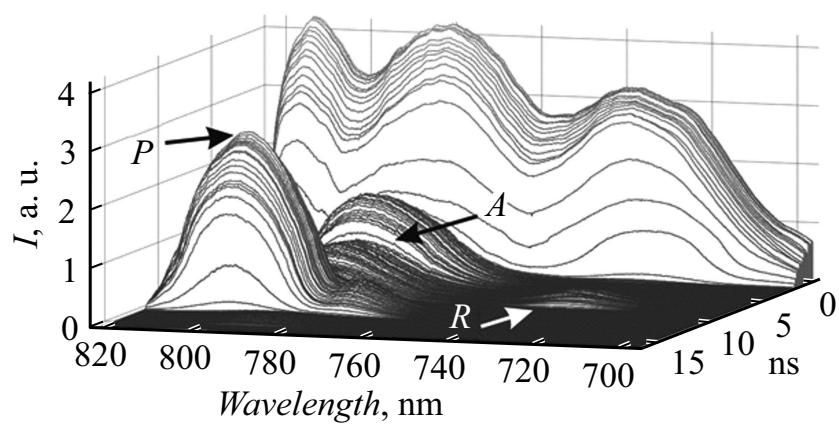

Рис. 2. Спектр лазерного импульса, прошедшего через филамент. $R-$ боковой сателлит, $P$ - постимпульс, время появления которого определяется частотой импульсов на выходе генератора, $A$ - падение интенсивности лазерного излучения, связанное с появлением бокового сателлита.

порядка $65 \mathrm{fs}$ с энергией до $4.5 \mathrm{~mJ}$. Частота следования задавалась равной $1 \mathrm{kHz}$. С помощью линзы 2 с фокусным расстоянием $50 \mathrm{~mm}$ в области перетяжки наблюдалось формирование филамента 3. Линзой 4, расположенной на двойном фокусном расстоянии линзы 2, излучение, прошедшее через филамент, направлялось на опаловый косинусный рассеиватель 5, закрепленный на входе кварцевого световода 6. Для подавления исходного излучения использовался светофильтр CC1 (7) с постоянным коэффициентом ослабления в диапазоне 700-850 nm. Выход световода был соединен со щелью спектрографа Spectra Pro 2300i (Princeton Instruments) (8). В качестве приемника использовалась ICCD-камера PI-MAX3 (16 bit, Princeton Instruments) (9). Излучение, прошедшее через филамент, регистрировалось с экспозицией $3 \mathrm{~ns}$ и шагом задержки экспозиции $t=0.1 \mathrm{~ns}$. Для управления лазерным комплексом и системой регистрации, а также для обработки данных использовался персональный компьютер 10 с соответствующим программным обеспечением.

В ходе проведения экспериментальных исследований была получена картина временно́й динамики спектра лазерного излучения, прошедшего через филамент, показанная на рис. 2. В качестве начала временно́го отсчета был взят момент времени, соответствующий максимуму интенсивности основного фемтосекундного импульса. При $t<2 \mathrm{~ns}$ спектр

Письма в ЖТФ, 2018, том 44, вып. 21 
Характеристики триплета O I

\begin{tabular}{c|c|c}
\hline$\lambda, \mathrm{nm}$ & Переход & Сила линии $\mathcal{S}$, a. u. \\
\hline 777.19 & & 59.9 \\
777.42 & $3 \mathrm{p}^{5} \mathrm{P}_{3,2,1}-3 \mathrm{~s}^{5} \mathrm{~S}_{2}^{0}$ & 42.8 \\
777.54 & & 25.7
\end{tabular}

* Здесь а. u. - атомные единицы.

основного импульса сильно смещен в антистоксову область спектра и преобразован в три отчетливо выделяющихся пика. Данная трансформация связана с проявлением фазовой самомодуляции в среде с керровской и плазменной нелинейностями [10]. На рис. 2 наблюдается быстрый спад интенсивности лазерного излучения, при этом время появления бокового сателлита $R$ на длине волны $\lambda \approx 735 \mathrm{~nm}$, связанного с расщеплением Раби уровней $\mathrm{O} \mathrm{I}$, составляет $t=5.3 \mathrm{~ns}$. Учитывая время экспозиции $3 \mathrm{~ns}$, можно предположить, что длительность излучения боковых сателлитов $t \leqslant 3 \mathrm{~ns}$. Интенсивность сателлита ниже интенсивности лазерного излучения более чем в 15 раз, а полуширина линии составляет примерно $22 \mathrm{~nm}$. Отметим, что появление пика Раби сопровождается падением интенсивности излучения (обозначено как $A$ на рис. 2). Известно, что взаимодействие мощного лазерного излучения на частоте $\omega$ с атомами кислорода вблизи перехода $3 \mathrm{p}^{5} \mathrm{P}-3 \mathrm{~s}^{5} \mathrm{~S}$ приводит к появлению боковых сателлитов на частотах $\omega \pm \Omega^{\prime}[7,8]$. Характеристики триплета О I приведены в таблице. Обобщенная частота Раби определяется как $\Omega^{\prime}=\sqrt{\Delta^{2}+\Omega^{2}}$, где $\Delta-$ отстройка частоты перехода от центральной частоты возбуждающего лазерного импульса, $\Omega=\mu F / \hbar$ - частота Раби, зависящая от приведенного дипольного матричного элемента $\mu$ и амплитуды электрического поля $F$. Дипольный матричный элемент вычисляется как $\mu=\sqrt{\mathcal{S}}$, где $\mathcal{S}-$ сила линии (значения $\mathcal{S}$ взяты из базы данных NIST [11] и приведены в таблице). Отстройка для лазерного импульса, смещенного в синюю область на $10 \mathrm{~nm}$ (рис. 2), составляет $\Delta \approx 0.026 \mathrm{eV}$. Следует отметить, что на приведенном рисунке отсутствуют боковые полосы, соответствующие линиям триплета. Так, для перехода $J^{\prime}=3-J=2$ и интенсивности $I=2 \cdot 10^{10} \mathrm{~W} / \mathrm{cm}^{2}$ должен наблюдаться пик в окрестности $717 \mathrm{~nm}$, что противоречит данным рис. 2, а также результатам работы [8]. По-видимому, это противоречие можно объяснить разрывом $L S$-связи

2* Письма в ЖТФ, 2018, том 44, вып. 21 
для уровня O I 3p 5 Р в сильном лазерном поле. Если возмущение, вызванное лазерным полем, значительно превосходит возмущение вследствие спин-орбитального взаимодействия, то состояния атома не могут быть описаны в базисе $|n, L, S, J, M\rangle$ [12]. При интенсивности лазерного излучения $I \sim 10^{10} \mathrm{~W} / \mathrm{cm}^{2}$ расщепление Раби уровней составляет $\hbar \Omega^{\prime}=0.08 \mathrm{eV}\left(J^{\prime}=1-J=2\right)$, что на два порядка больше мультиплетного расщепления $\Delta_{L S}=7 \cdot 10^{-4} \mathrm{eV}$ для атома кислорода. В этом случае электрическое поле связывается с полным угловым орбитальным вектором L. Для перехода $n l S L-n^{\prime} l^{\prime} S L^{\prime}$ сила линии $\mathcal{S}$ определяется соотношением [13]:

$$
\mathcal{S}=\left|\left\langle n L\|D\| n^{\prime} L^{\prime}\right\rangle\right|^{2}=\frac{1}{2 S+1} \sum_{J J^{\prime}} \mathcal{S}\left(l S L J ; l^{\prime} S L^{\prime} J^{\prime}\right) .
$$

В знаменателе формулы (1) приведено значение мультиплетности. Из (1) получаем $\mathcal{S}=25.7 \mathrm{a}$. u. Следовательно, для $\Delta \approx 0.026 \mathrm{eV}$ средняя интенсивность лазерного излучения равна $I=2.5 \cdot 10^{10} \mathrm{~W} / \mathrm{cm}^{2}$ при $5 \leqslant t \leqslant 8 \mathrm{~ns}$. Полученная величина интенсивности лазерного излучения, скорее всего, является средним значением интенсивности усиленного в регенеративном усилителе спонтанного излучения и постимпульсов на временно́м интервале 3 ns. Отметим, что в работах [7,8] сателлиты, связанные с расщеплением Раби уровней, наблюдались для второго пикосекундного импульса, для данных экспериментальных условий сателлиты генерируются усиленным спонтанным излучением регенеративного усилителя и постимпульсами. Таким образом, наличие бокового сателлита в спектре прошедшего через область филаментации лазерного излучения может указывать на разрыв спин-орбитальной связи. Регистрация расщепления Раби уровней О I и падение интенсивности на основной длине волны излучения позволяют также оценивать интенсивность лазерного излучения, следующего за основным фемтосекундным импульсом (усиленное спонтанное излучение и постимпульсы).

Исследование трансформации лазерного импульса выполнено при финансовой поддержке гранта Российского научного фонда (проект № 14-50-00034), анализ разрыва $L S$-связи проведен при поддержке гранта РФФИ (№ 17-02-00802 А), спектр лазерного импульса получен с использованием оборудования уникальных стендов и установок ЦКП „Лазерные методы исследования конденсированных сред, биологических объектов и мониторинга окружающей среды“ ИАПУ ДВО РАН.

Письма в ЖТФ, 2018, том 44, вып. 21 


\section{Список литературы}

[1] Пилипецикий Н.Ф., Рустамов А.Р. // Письма в ЖЭТФ. 1965. В. 2. С. 88-90.

[2] Чекалин С.В., Кандидов В.П. // УФН. 2013. Т. 183. № 2. С. 133-152.

[3] Couairon A., Mysyrowicz A. // Phys. Rep. 2007. V. 441. N 2-4. P. 47-189.

[4] Kul'chin Y.N., Golik S.S., Proshenko D.Y., Chekhlenok A.A., Postnova I.V., Maior A.Y., Shchipunov Y.A. // Quant. Electron. 2013. V. 43. N 4. P. 370-373.

[5] Bukin O.A., Babii M.Y., Golik S.S., Il'in A.A., Kabanov A.M., Kolesnikov A.V., Kulchin Yu.N., Lisitsa V.V., Matvienko G.G., Oshlakov V.K., Shmirko K.A. // Quant. Electron. 2014. V. 44. N 6. P. 563-569.

[6] Ilyin A.A., Golik S.S., Shmirko K.A. // Spectrochim. Acta B. 2015. V. 112. P. 1622

[7] Compton R., Filin A., Romanov D.A., Levis R.J. // Phys. Rev. A. 2011. V. 83. N 5. P. 053423.

[8] Heck G., Filin A., Romanov D.A., Levis R.J. // Phys. Rev. A. 2013. V. 87. N 2. P. 023419.

[9] Labutin T.A., Lednev V.N., Ilyin A.A., Popov A.M. // J. Anal. Atom. Spectrom. 2016. V. 31. N 1. P. $90-118$.

[10] Апексимов Д.В., Букин О.А., Быкова Е.Е., Гейни, Ю.Э., Голик С.С., Землянов А.А., Ильин А.А., Кабанов А.М., Матвиенко Г.Г., Ошлаков В.К., Петров А.В., Соколова Е.Б. // Прикладная физика. 2012. № 6. С. 14-22.

[11] База данных атомных спектров NIST [Электронный ресурс]. URL: https:/www.nist.gov/pml/atomic-spectra-database (дата обращения: 22.03.2018)

[12] Dubreuil B., Chapelle J. // Physica B+C. 1978. V. 94. N 2. P. 233-250.

[13] Собельман И.И. Введение в теорию атомных спектров. М.: Физматгиз, $1963.640 \mathrm{c}$. 